\title{
The structure of professional competence of a teacher in Russia
}

\author{
Irina Mikhailovna Zakharova ${ }^{1}$, Liliya Mustafovna Fayzrakhmanova \\ ${ }^{1}$ Faculty of Pedagogy, Institute of socio-pedagogical technologies and resources; the city of Naberezhnye Chelny, Republic of Tatarstan, \\ Russia \\ ${ }^{2}$ Faculty of Foreign Languages and Methods of Teaching, Institute of socio-pedagogical technologies and resources; the city of \\ Naberezhnye Chelny, Republic of Tatarstan, Russia
}

Email address:

zaharova-i@mail.ru(I. M. Zakharova), liya2406@rambler.ru(L. M. Fayzrakhmanova)

\section{To cite this article:}

Irina Mikhailovna Zakharova, Liliya Mustafovna Fayzrakhmanova. The Structure of Professional Competence of a Teacher in Russia. Education Journal. Vol. 2, No. 5, 2013, pp. 186-191. doi: 10.11648/j.edu.20130205.11

\begin{abstract}
The change of the educational paradigm in Russia leads to a need to revise not only the content of education, but also the role and the place of a teacher in the educational process, and determination of the level of professionalism of teachers. In modern conditions of modernization of education, together with the transition from "knowledge" approach to competence approach, the professional functions, and accordingly, the requirements to psychological and pedagogical competence of a teacher increase. In modern Russia new Federal Educational Standards (FES) are adopted in the field of General education. Thus, a number of questions and contradictions appear: the introduction of new educational standards should entail modification of the content and criteria of estimation of professional competence of teachers. The article presents the experience of the teaching staff of the Institute in the aspect of the training of future teachers and educational psychologists in Russia.
\end{abstract}

Keywords: Pedagogical Competence, Expert Evaluation, the Structure of Pedagogical Competence of a Teacher, Developmental Education, the Subject of the Training Activities, the Internship Program for Students

\section{Introduction}

Modern social requirements to school education in Russia are defined in new Federal Educational Standards (FES). They reflect the transition from the traditional subject -reproductive education, in the basis of which the idea of a translation and assimilation of knowledge (information) to the competence-based approach is laid [4].

The concept of «competence» has become the key concepts in connection with the modernization of education in Russia. [2]. In the new socio-economic, political conditions of Russia's development it is necessary to ensure the adequacy of the education system to the changed needs of the economy and new social system and, of course, to the needs of the individual in these new conditions. On the other hand, the reform is caused by the integrative processes, in particular Russia's entry into the Bologna process. According to the new FES teaching at school should be based on the competence-based approach, which means education for life, for the successful socialization of a school graduate in the society and for his personal development. There are definite changes in the way of a student evaluation: the assessment gives the opportunity to plan his educational outcome and to improve it in the process of continuous self-assessment. The competencebased approach assumes a variety of forms of selforganization, meaningful activity of students on the basis of their own motivation and on the responsibility for the result.

One of the main requirements to the activity of a teacher in contemporary Russia is its responsibility for the result of education. The result is defined as being not the amount of acquired information, knowledge, but the ability of a school graduate to apply this knowledge in a variety of situations. And the emphasis in training activities here should be put on the independence - on the initiative and responsibility of pupils and students themselves.

In the FES "competence" is understood as the "qualitative characteristic of the implementation of knowledge formed in the educational process, generalized ways of activity, cognitive and practical skills and competencies that reflect the ability of (willingness) of a person actively and creatively use the obtained education 
for the solution of personal and socially significant educational and practical tasks, and for effective achievement of life goals» [4].

To outline the main idea of this definition, the competence is the acquired human quality, which enables to carry out professional activity successfully. So, it can be concluded that at the present stage of development of our society, the requirements to the professional competence of the teacher and his / her professional training are changing.

New requirements to the pedagogical competence change, in fact, the teacher's activities: the purposes and content of the activities of a teacher and his methods of teaching are changing. The results of the pedagogical activity are evaluated differently.

Issues related to professional competence of teachers and teachers-psychologists, providing psychological and pedagogical support of the educational process, are increasingly relevant in connection with the transition to the new standard of education. Therefore, it is necessary to change the system of preparation of future specialists in the system of higher professional education.

A modern Russian school needs a teacher, who is able to organize and manage the educational activity of the student on the basis of an understanding of its laws and psychological peculiarities. One of the requirements to pedagogical activity of a teacher - is the ability to form the subject of a training activity and the development of a schoolchild training skills. This, in principle, is impossible without the implementation of principles of developing education into the activities of teachers. It should be noted that the system-activity approach, which is the main approach in the transition to the new standards of education, can be realized only in the framework of the system of developmental education [1].

\section{The Main Part}

This article presents the experience in the research of the content and of the criteria of estimation of professional competence of primary school teachers [3]. We offer a comprehensive approach to the evaluation of educational competence of a teacher of elementary school, where competence is considered as an externally specified requirements relating to a teacher as a subject of educational activities (the criteria of what must be fulfilled), and competence there is an internal feature, the ability of an individual to solve professional tasks and obtain results.

On the basis of a comparative analysis of different theoretical approaches and requirements of the FES of general education of the second generation the structure of professional competence of a primary school teacher of initial classes was defined. The group of experts using the non-graduate scale by Dembo-Rubinstein evaluated the importance of the specific competencies for the activities of teachers of primary classes (the method of expert estimations and the method of scaling by DemboRubinsteinn had been used) [3].
To achieve the objectives of the research we have conducted the empirical research, the process of which was the following: each expert was supplied by an assessment form. Each competence (professional knowledge, teaching skills, social competence, legal competence, organizational competence, communication skills, reflective and analytical skills, information competence and performance) presents a vertical line (each-10cm.length). The bottom of the line identifies the complete absence of this competence $(0$ points), and the top - the maximum expression of the competence (100 points). The experts were offered to evaluate the required level of the competence of an ideal teacher, indicating by the cross the level of his development

The experts of our research (in the amount of 35) were the school principals or head teachers of primary classes, who knew the methods of subject teaching; University teachers who knew the methodology and theory of education; teachers of initial classes, working on traditional and developing systems of teaching; certified experts of the municipal department of education with experience in certifying Commission; University teachers, knowing the psychology of learning and the basics of system-active approach ; specialists of information and methodological center of the city Department of education and the heads of city Department of education. The results of this phase of the study can be presented in the form of a table (table 1).

Table 1. Peculiarities of the expert evaluation of professional competences of teachers

\begin{tabular}{lll}
\hline Special competence & $\mathbf{M}$ & $\boldsymbol{\delta}$ \\
\hline Teaching skills & 87,29 & 11,37 \\
Effectiveness of the activity & 85,63 & 12,63 \\
Communicative skills & 82,94 & 12,39 \\
Organizing skills & 82,46 & 12,51 \\
Analytical-reflexive skills & 81,69 & 17,37 \\
Professional knowledge & 76,44 & 20,13 \\
Social competence & 74,60 & 19,14 \\
Informational competence & 73,91 & 17,39 \\
Juridical competence & 70,23 & 23,65 \\
\hline
\end{tabular}

Note: $\mathrm{M}$ - average figure, $\delta$ - standard deviation

According to the table each of the suggested types of competencies were evaluated by the experts high enough. Note that the highest score had been given to teaching skills and effectiveness of the activities. Most likely, the experts consider them to be fundamental in the professional competence of a primary school teacher. These results reconcile with the requirements of educational standards, which state that the compliance of the employee to the requirements of the qualification and is determined by the results of attestation of a teaching staff, based on the results of development of the students of the basic education program and on the dynamic indicators of their educational achievements.

Although other types of competences were estimated by 
experts lower, we draw your attention to the fact that none of the proposed competences received less than 70 points out of 100 possible. Consequently, all other types of special competences are also important for professional success of teachers together with the competencies which got maximum points.

The second stage of our research [3] was the determination of the content of each special kind of professional competence of a teacher. With this purpose there were used the methods of ranking and expert assessments. The experts were offered a list of specific professional skills (from 8 to 15 names and descriptions of competences). Those competencies were needed to be ranked according to the importance for the teacher's activity [3].

By finding the average rank of specific competences 4-7 first concrete competencies in each certain type of competencies had been selected. The other criteria were not used in the further work, as having a low value for the work of a primary school teacher. Thus, we have determined the structure of each different type of a competence of a teacher.

Here we'll describe in details the structure of each competence given in table 1 . So, the structure of a social competence according to the expert is the most significant (it has received the highest rank, in order of importance). It consists of the following individual kinds:

1. Realization of the activity in accordance with moral, ethical and legal standards;

2. The ability to build positive interpersonal relations in children's group;

3. The ability to form positive microclimate within the organizational culture in educational institutions;

4. The ability to communicate effectively with parents, teachers of educational institution on the matters of upbringing and development of pupils.

According to our results, the teacher has to build an effective interaction with parents, colleagues to solve pedagogical problems in order to solve the moral, ethical and legal norms. That means that a teacher has to work in a team. In the structure of social competence is the ability to build positive interpersonal relations in children's group, which requires from teachers to conduct a reflection of the actual situation in the classroom and to plan the interaction of pupils in children's group; to simulate the conditions of microclimate formation in the classroom.

Let us analyze a communicative competence in details. The structure of this competence includes the following specific types (in descending order of importance of an individual type):

1. The proficiency in establishing contact with learners of different ages, with their parents (or surrogate parents), work colleagues;

2. The ability to organize the communicative activity of pupils, including the development of speech communication and etiquette;

3. Skills in interaction with other specialists in solving (pedagogic) problems or in the project implementation;
4. Knowledge of methods of diagnostics in stating the reasons of conflict situations.

It should be noted that the first individual type of the communicative competence was given the greatest importance on the results of experts' evaluation; the other three types are about on the same level of importance for the professional success of a teacher. As you can see, this type of the competence is linked with expertise in the field of developmental psychology, because without the knowledge of psychological patterns of age development there will not be any effective interactions with the students According to the experts the most important for teachers is to establish contacts with students, it creates a new content and methods of activity of a teacher in a modern society.

Let us analyze the next kind of the competence of a teacher - a professional knowledge. The structure of the professional knowledge consists of the following particular types (in the order of importance):

1. Theory of teaching of junior schoolchildren

2. Modern pedagogical technologies of teaching methodology

3. Theory and methods of education of junior schoolchildren
4. Age psychology
5. Pedagogical psychology
6. Russian language

We can agree with the experts that a teacher of initial classes must possess the theory and the methods of teaching and upbringing. In new social realities a teacher needs to have the knowledge of developmental and educational psychology for the successful solution of pedagogical problems in his professional activity which are the basic minimum requirements for the professional knowledge of teachers. It should be noted that a new requirement compared to the previous requirements to professional knowledge of teachers constituted the requirements of psychological knowledge, which are fundamental in the work of a teacher.

Look at the structure of a legal competence of a teacher that contains the knowledge of the following standards:

1. Standards of General primary education of the second generation

2. The Convention on the rights of a child

3. The Law of the Russian Federation «About education»

4. Job description (at work)

5. The Law of the Russian Federation «Basic guarantees of the rights of a child in the Russian Federation»

6. The Constitution of the Russian Federation

7. Internal regulations of the educational institution

Note that the legal basis of a pedagogical activity is a new requirement to the professional competence of a teacher. The structure of this type of the competence includes the normative legal acts, regulating pedagogical activity of a teacher. Violation of these norms and rules in principle makes it impossible for teachers to work at school; this explains the composition of a legal competence. Unfortunately, in the educational practice we encounter 
private violations of the rights of a child, the lack of legal protection of teachers, etc.; therefore, the experts emphasize this type of the competence and include it in the professional competence of a teacher.

Let us dwell on the information competence. The following specific types of the competence make the structure of it on about the same level of importance:

1. Skills in the use of existing information technologies, including digital educational resources

2. Basic work with text editors, spreadsheets

3. The right choice of software of educational and methodological support, including digital educational resources (in accordance with the educational objectives and principles).

4. The skills to construct and use the lesson didactic materials with the help of computer software.

5. Basic work with multimedia equipment

6. The skills of evaluation of the effectiveness and outcomes of training of younger pupils on the subject (or on the program), considering the development of knowledge, learning skills, development of creative experience, the cognitive interest of the students, with the use of computer technology, including word processors and spreadsheets.

Summarizing the results of this competence, we note that in accordance with the new educational standards, special attention is paid to information literacy of teachers. Without mastery in working with multimedia resources it is not possible to achieve the didactic purposes. In principle it is impossible to organize the personal development of a pupil, of the reflection and the evaluation, of the performance of training and education. It is not a secret that the information literacy of teachers often lags behind the skills of students in this field. Although the experts excluded the skills of using e-mail and browsers or Internet resources from the structure of the information competence, we think that the requirements for this type of the competences will only increase together with the socio-cultural development of this type in the world.

Let us turn to the following competence of a teacher - the effectiveness of the activities. This type of the competence caused, probably, a wide resonance in the educational environment. Note that a narrow understanding of this criterion in the work of a teacher, when effectiveness is understood only as the assessment of students' learning achievements without analysis of the pedagogical process (dynamics of results of pedagogical activity) may violate the implementation of systemic action principle, which is one of the main innovations of the FES.

These are the results of expert evaluation. The following specific types of the competence were included in the structure of the effectiveness of the activity:

1. The proficiency of pupils of primary classes in logical actions of comparison, analysis, synthesis, type classification; in finding analogies and causality.

2. Pupils 'ability to use different ways of searching, collecting, processing, analyzing, arranging and interpreting information in accordance with communicative and cognitive tasks and technologies of teaching subject, including the introduction of a text using the keyboard, the fixation (recording) in digital form and the ability to analyze the images, sounds, measured values, prepare a speech and to act with audio, video and graphic support; observe the norms of the information selectivity, ethics and etiquette;

3. The implementation of training actions with language units and use of knowledge for decision of cognitive, practical and communicative tasks («Russian language», «Mother tongue»)

4. The use of basic mathematical knowledge to describe and explain the surrounding objects, processes and phenomena, as well as assessment of their quantitative and spatial relationships

5. Reading aloud and in silent, analysis and transformation of artistic, popular science and educational texts using the elementary literary concepts («Literal reading»)

6. The performance of oral and written arithmetic actions with numbers and numerical expressions, solving of text tasks, action in accordance with algorithms, arranging of the simplest algorithms, working with tables, charts, graphs and diagrams, chains, sets (Mathematics)

It should be noted that the first individual type of the competence, that is teaching logical analysis, synthesis and generalization is noted by the experts as the most significant result of the activities of a teacher, all the rest of the specific types of competences are about on the same level of importance. These data are consistent with the new requirements set out in the FES; the transition from «knowledge» paradigm training to the developing system of training is a new ideology of teaching. Consequently, evaluation of the results of the activity of teachers must include procedures that assess the level of development of theoretical thinking of a pupil, level of development of general skills in the dynamics of their formation, which is an absolute novelty in the education system.

Now we'll analyze the composition of methodical skills. All these particular types of the competence are approximately at the same level of significance:

1. The ability to form in pupils the operations of comparison, analysis, synthesis, elementary classification according to gender grounds, establishing analogies, relating to known notions.

2. The ability to form in pupils different ways of searching information, including ICT, processing, analysis and interpretation of data in accordance with the training task; to help them to use dictionaries and reference books for pupils.

3. The ability to help pupils to organize the competence laid down in the requirements for the development of learning material of concrete academic disciplines

4. The ability to organize in pupils the skills of participation in the educational dialogue and the skills of transmission of the received information in a coherent narrative. 
5. The ability to help pupils to form the sign-symbolic representation tools for creating models of the studied objects and processes, schemes for the solution of educational and practical tasks.

6 . The ability to help pupils to get the basic information about the essence and peculiarities of the objects, processes and phenomena of reality (natural, social, cultural, technical, and other) in accordance with the content of a particular academic subject of an elementary school

The received composition of methodical skills seems to be the logical consequence of the previous competence that is of the performance of activities. So the performance requires from pupils the knowledge of the logical operations of analysis, synthesis and compilation, therefore, a teacher must possess the methodological skills of formation of these operations in schoolchildren (note that the level of significance of this type of competence is in the first place in both cases). If the performance requires the mastering of the main results on the subjects, the competence in a methodical plan is needed - the ability to form a competence on subjects in pupils. In other words, the effectiveness of the activities is directly connected with the methodical skills of a teacher. The higher the level of the methodical competence of a teacher, the better results he demonstrates in his work.

The structure of reflective and analytical skills includes the following specific types of competencies (approximately the same level of importance of the components of the competence is received):

1. The ability to set goals to achieve success in the subject area of pupils and the achievement of higher results in transdisciplinarity.

2. The ability to assess the effectiveness of the teaching activity.

3. The ability to assess the current state and dynamics of a child development in the basic educational program.

4. The ability to assess the current state and dynamics of intellectual, moral, volitional development of a child.

5. The ability to assess the readiness of pupils to educational action (to general skills)

6. The ability to highlight the difficulties in the development of educational subjects, which a pupil can have in a primary school

The interpretation of this type of competence allows to trace some connection with the above mentioned competencies. For example, the ability to assess the dynamics of the development of a child's educational program is linked to the performance of a teacher, the ability to highlight the difficulties of a pupil is connected with methodological skills of a teacher; the ability to assess the level of psychic development of a pupil is linked to with the professional knowledge in the field of developmental and educational psychology.

Let us turn now to the organizational skills of a teacher. The composition of this competence includes the following forms (all submitted structural components of organizational skills have about the same level of importance of experts` evaluation):

1. The ability to organize joint and individual activities of children.

2. The ability to organize the work on promotion of a child within the framework of individual educational trajectories.

3. Possession of modern technologies of designing the educational environment

4. Knowledge of the principles of organization of the educational environment (including educational and information-educational environment)

5. The ability to take into account the internal and external conditions for the execution of its activities and the activities of pupils in achieving planned outcomes.

6 . The ability to choose between several programs (tools) the most suitable program (the means) to achieve this goal.

Organizational skills of a teacher also undergone some changes in the content and you can see some of the linkages with other types of the competences. For example, the ability to organize joint activities of children is impossible to implement without the communicative competence, without the knowledge of the age and individual characteristics of children. The ability to organize the work on promotion of a child within the framework of individual educational trajectory is impossible without a certain level of development of reflective and analytical skills of a teacher. The ability to take into account the internal and external conditions of pedagogical activity is also associated with reflective and analytical skills.

\section{Concluding Part}

Thus, in modern Russia there are changes in the requirements to pedagogical activity of a teacher. Our study concretizes the structure of professional competence of a teacher of an elementary school. It becomes obvious that the process of teaching of future primary school teachers and teachers-psychologists should be organized in a completely different way.

In the Institute of social-pedagogical technologies and resources (Republic of Tatarstan, Naberezhnye Chelny) the task was determined for the professorial-teaching staff: to prepare teachers and teachers-psychologists, capable to realize the developmental education at schools, that most fully corresponding with the new FES. We'll give a brief account about the experience in the organization of students training on a specialty «A primary school teacher » and of the specialty "Pedagogic and psychology" at Scientific Research Institute of the city of Moscow. Polarity and alternative of traditional and developmental education requires building the training of teachers in a different way. It is necessary to create conditions when a student understands the entity of components of developmental education, and understanding of its capabilities and limitations which ensures the formation of an ability to construct the content of school subjects and the ability to 
organize the research activity of schoolchildren.

In terms of realization the mentioned approach we arranged the system of interaction with the Scientific Research Institute of Moscow city which took place in our Institute in 2008. In the framework of this cooperation with the help of Scientific Research Institute the Program of training of the students in Moscow schools was developed.

When developing the training program as strategic concepts there were the main components of developmental education, such as «learning objective», hypothesis, and how to work with it, training actions for schoolchildren, for example, the actions of control and self-control, evaluation and self-evaluation. The program of the internship involves the analysis of the psychological content of the fundamentals of developmental education as well as the specific practical implementation of activity-based teaching at school.

The program is for students who have studied traditional courses of psychology, including the fundamentals of developmental education in the framework of pedagogical psychology. As a whole the program of the internship was defined by the basic principles of developmental education, and so the organization of the sessions for the studentstrainees was built by the teaching staffs of the primary school of Moscow secondary school №1277, which work according to the system of developmental education by Elkonin - Davydov [1].

It was necessary to focus the students' attention to the psychological-pedagogical problems of the modern school, to determine the conditions of overcoming the problems identified and the conditions for making schoolchildren accept educational objectives (mentioning the students' understanding of the essence of the concept of the notion «Task»).

The main direction of work on the next stage was the selection of essential characteristics of the hypothesis, with which a teacher and students deal in the class. Students, being in the position of learners, distinguished the pedagogical methods of work with the hypothesis, reproduced the scheme in relation to the learning session. After the observations at the lessons at school the analysis of a pedagogical work with the hypothesis was carried out, the main stages of work with the hypothesis were identified and the most effective techniques and methods of educational work were discussed.

It should be noted that another part of the training Program was mastering by the students the principles of classes arranging with learners in cogitative activity pedagogy. In the framework of this aspect, students under the guidance of professorial-teaching staff of ScientificResearch Institute designed the content of developmental education, identified the problems of Russian identity, reflexed the area of knowledge «anthropology abilities», and determined the positions of «didactist - methodistanthropologist».
The program of the internship aroused interest not only among students, but also among the teachers of the University, who familiarized with the results of the internship. Such organization of the training of future professionals, including both theoretical foundations of learning the basics of developing education, and practical implementation of formed competencies into the practice of school helped to increase the level of professionalism of future primary school teachers' and teachers-psychologists.

Taking into account the fact that in our Institute the prepared students are ready to work in the system of developmental education in the framework of the Federal experimental platform in the schools of our city, we conducted the monitoring of the first graduates, who received such training. It should be noted that the graduates increased their professional self-esteem and confidence in performing their professional functions. On the other hand, the urban school education has received highly motivated specialists able to solve practical tasks of psychological and pedagogical support of schoolchildren.

The teaching staff of our Institute is focused on the practical functionality of the students to address the problems of training of pedagogical personnel, capable to work in the new social environment.

\section{Conclusions}

1. Thus, the structure of individual types of professional competence of a teacher was defined and the objectives were achieved. In accordance with the new requirements of the Federal Educational Standard the structure of the professional competence of a teacher of an elementary school was established.

2. In practical terms, the obtained results allow to define the procedure of preparation of future teacher of primary school more clearly, to develop specific requirements to final result in terms of formation of professional competence of teachers of elementary school which are relevant to requirements of the FES.

\section{References}

[1] Davydov B.B. The theory of developing education - M., 1996

[2] Mitina L. M. Psychology of work and professional development of teachers: textbook. Manual / L.M. Mitina. M: «Academy», 2004 p. 12

[3] Empirical testing of models of the assessment of professional competencies of primary schools teachers: research report (final /VNTEZ/the head V.A. GuruzchapovGKP-612;№ 02201056458 2010-M, 147p.

[4] The Federal state educational standard of the primary education. Approved by the order of Ministry of education and science of Russia from 06.10.09, № 373 / Bulletin of education of Russia. - № 2 - 2009. - p. 45-73. 